\title{
CIÊNCIA E RELAÇÕES SOCIAIS NO CAPITALISMO: ELEMENTOS PARA O DEBATE
}

SCIENCE AND SOCIAL RELATIONS IN CAPITALISM: ELEMENTS FOR DEBATE

\section{Renata Martins de Freitas ${ }^{1}$}

RECEBIDO EM: 09/07/2017 | APROVADO EM: 05/08/2017

DOI: $10.5902 / 2317175823872$

\section{RESUMO}

O presente trabalho busca empreender reflexões e trazer elementos para colaboração com o debate acerca da ciência, tecnologia e seus efeitos para a vida humana. É realizada aqui uma revisão de bibliografia a partir de autores que têm como referencial teórico o marxismo. Compreende-se que a ciência, a tecnologia e a produção do conhecimento não existem isoladas das relações sociais como um todo e são parte do desenvolvimento das forças produtivas, neste caso, no âmbito do capitalismo. Isso quer dizer que não são neutras e seus efeitos estão relacionados com os efeitos do capitalismo na vida humana, bem como das relações sociais engendradas na ordem burguesa, baseadas na forma-mercadoria e que alienam o humano de sua própria produção. Considera-se que se faz necessário pensar na superação da ordem burguesa para que se possa pensar na direção da ciência atuando para a lógica da emancipação humana.

Palavras-chave: Ciência; Marxismo; Emancipação.

\footnotetext{
1 Assistente Social (UERJ), cursando mestrado em Ciências Sociais na Universidade Federal Rural do Rio de Janeiro (UFRRJ). e-mail: re.marfre@yahoo.com.br
} 
CIÊNCIA E RELAÇÕES SOCIAIS NO CAPITALISMO:

ELEMENTOS PARA O DEBATE

\section{ABSTRACT}

This study AIMS to undertake reflections and bring elements for collaboration with the debate about science, technology and its effects on human life. It is Performed here a bibliography review from authors whose theoretical Marxism. It is understood that science, technology and the production of knowledge are not isolated from the social relations as a whole and are part of the development of the productive forces, in this case, under capitalism. This means que they are not neutral and its effects are related to the effects of capitalism in human life and social relations engendered in the bourgeois order, based on the commodity form and alienate the human from its own production. It is considered that it is necessary to think of overcoming the bourgeois order so that you can think in the direction of science working for the logic of human emancipation.

Keywords: Science; Marxism; Emancipation.

Queremos saber,

O que vão fazer

Com as novas invenções Queremos notícia mais séria Sobre a descoberta da antimatéria

E suas implicações $\mathrm{Na}$ emancipação do homem

Das grandes populações Homens pobres das cidades

Das estepes dos sertões (Gilberto Gil) $^{2}$

\section{Introdução}

Gilberto Gil incita-nos em sua canção "Queremos Saber", a questionar quais as implicações para o humano das "novas invenções". Traz à tona, em outro trecho não citado aqui, que se trata "da ilusão do poder", numa menção às relações que circundam o mundo das "descobertas científicas". Entre as inquietações que podemos perceber na canção, talvez a maior delas seja: de que maneira essas "invenções" têm impacto para a humanidade, sobretudo as pessoas mais pobres? E mais, não questiona quaisquer "impactos", mas aqueles que levem à emancipação humana.

$\mathrm{O}$ presente texto pretende trazer elementos para o debate acerca da relação ciência, tecnologia e sociedade, sob a ótica do referencial teórico marxista, que, conforme avaliamos, ilumina com mais clareza e coerência reflexões sobre as relações sociais no âmbito do capitalismo.

2 Versos da canção "Queremos Saber", composta por Gilberto Gil, importante cantor e compositor baiano nascido em 1942. A canção cujo verso encontra-se na epígrafe, traz importantes questionamentos epistemológicos, enfatizando a importância dos conhecimentos produzidos pela ciência para emancipação humana, questões que coadunam com aquelas levantadas ao longo deste artigo. 
Apesar de parecer uma pretensão grande, trata-se de um modesto texto que possui proposta igualmente modesta, ainda que tente empreender questionamentos que levem a caminhos "densos" e frutíferos em debates que não se esgotariam no espaço destes parágrafos. Não pretendemos dar respostas e resultados prontos, mas trazer elementos para um debate. Até porque a pesquisa, os questionamentos e a teoria não podem prescindir da preocupação com o movimento da realidade, que é dinâmica e contraditória.

A proposta inicial é empreender uma revisão bibliográfica sobre efeitos da ciência e da tecnologia para a sociedade. Tal como o questionamento de Gil. Questionamento este que tem uma posição no que tange à produção do conhecimento científico. Posiciona-se no sentido de reconhecer que esses conhecimento, ou esses conhecimentos devem ter implicações na vida das pessoas, na vida dos homens comuns. E não quaisquer implicações, mas aquelas que tenham uma direção emancipatória. Esse posicionamento em muito se assemelha com o que nos traz a teoria marxista.

A teoria em tela, todavia, aprofunda suas análises sobre a ciência e a tecnologia, relacionando-as às relações sociais existentes no modo de produção capitalista. Modo de produção este que tem produzido barbárie, mercantilização das relações e espoliação do humano. Diante das reflexões de autores marxistas buscamos essa relação, que retira da ciência e da tecnologia as ideias de neutralidade, autossuficiência e independência em relação à ordem social vigente.

\section{A ciência e as relações sociais no capitalismo}

Vemos nas reflexões empreendidas por Lowy (1982), Mészáros (2014) e mesmo em Frigotto (2014) que falar em ciência e em tecnologia remete grande parte das pessoas a pressupostos como neutralidade e metodologia implicada no distanciamento de juízos de valores.

Mészáros argumenta que a aparência existente é a de que a ciência constitui uma forma de conhecimento com autoridade indiscutível, baseada em metodologias que apregoam a neutralidade e a autossuficiência, desprovida de ideologia. Mais eficiente parece a produção de conhecimentos quanto mais distante da produção de ideologias ela aparece. No referido autor e também em Frigotto, vemos a possibilidade de desconstrução do argumento da neutralidade científica. O pressuposto do qual partimos neste trabalho é aquele que esclarece que a ciência e a tecnologia, muito embora pareçam entes autônomos, não existem no "vazio". Elas são construções que devem ser contextualizadas política, social e historicamente. Há uma mistificação própria das contradições no âmbito da ordem capitalista que traz a ilusão de que os problemas contemporâneos serão resolvidos dados os progressos da ciência e da tecnologia. Todavia, essa visão simplesmente desconsidera que não se pode fazer ciência fora do contexto histórico, econômico, social e político. 
As aparências a que nos referimos neste texto fazem com que ciência, tecnologia e produção do conhecimento sejam analisadas tendo em vista o que seriam seus efeitos positivos ou negativos para a humanidade, como se elas pudessem produzir tais efeitos de maneira descolada da totalidade das relações sociais e da ordem social em vigência.

O referencial adotado por nós, considerando a relevância das relações sociais em geral para o que é chamado "desenvolvimento da ciência e da tecnologia", pondera sobre os impactos da forma como as forças produtivas se desenvolvem e, consequentemente, a ciência e a tecnologia. Elas não são dadas em um grande "vácuo", afinal, como bem afirma István Mészáros (2014). A visão da autonomia científica, segundo o autor, contribui para a manutenção da ordem vigente, tendo relevância no estreitamento das brechas de possibilidades que vislumbrem alguma transformação dessa ordem, que, segundo Frigotto (2014), traz consigo, inevitavelmente, a barbárie e o "aniquilamento das bases sociais e materiais da vida humana".

Falar das relações entre a ciência e a sociedade também implica na tentativa de desconstruir a noção de neutralidade que aparentemente está vinculada à primeira. Para tal, consideramos importantes, ainda que não sem críticas, as contribuições de pensadores que buscaram empreender reflexões sobre os efeitos da ciência e da técnica para o conjunto da sociedade, considerando também haver relações políticas imanentes ao fazer científico.

Vemos em Bertrand Russell (1976) um esforço em elencar alguns efeitos da ciência sobre a vida humana. Ele avança em reconhecer a existência de outras formas de conhecimento que não o científico, sendo este ainda recente se pensarmos na história da humanidade. A ciência, todavia, foi um conhecimento ou uma forma de conhecer que tem aspecto revolucionário, tendo hoje potencial de legitimidade e de transformações da vida humana, inclusive transformações políticas.

Como a proposta de Russell parece ser a de elencar efeitos, ele trata das descobertas da pólvora e da bússola que provocou a subsunção de sujeitos aos reis e tornou possível a Era dos descobrimentos, respectivamente. Traz à tona o quanto o telégrafo ampliou o poder do governo central, diminuindo poderes de subordinados distantes, assim como a eletricidade teve efeitos diversos sobre as vidas de homens e mulheres. Elenca também efeitos políticos da emergência do petróleo como fonte esgotável importante. Fala sobre aquilo que chama "progresso da aviação", das estatísticas e da biologia. Pondera que a psicologia de massas terá grande importância política pela arte da persuasão, mas será acessível em maior escala às classes dirigentes, sendo conhecimento não acessado pelas massas. Aqui, Russell já menciona a existência de uma desigualdade de acesso ao conhecimento científico e o que ele denomina seus "efeitos", mas não parece trabalhar com o conceito de classes sociais, tal como vemos em autores como Frigotto, Mészáros e, sobretudo, Marx. 
Muita embora se observe em Russell um esforço no sentido de compreender que a ciência não está deslocada da sociedade, seu modo de apresentar essa realidade é criticado por Mészáros (2014) porque traz o desenvolvimento da ciência e da tecnologia como conjunto autônomo de constructos, como se por si só provocassem efeitos positivos ou nefastos na vida dos homens e mulheres comuns.

Outro autor preocupado com as implicações da produção do conhecimento e da técnica para os sujeitos sociais é Herbert Marcuse (1967). O autor da Escola de Frankfurt elabora seus argumentos a partir da noção de que o tecnológico também é político, relacionando ciência, tecnologia e dominação. Ele fala sobre a racionalidade científica, seu aparato e sobre a tensão entre razão e as necessidades da população, que, segundo ele, "[...] tem sido objeto da razão, mas raramente seu sujeito" (p.144). Marcuse anuncia aí um caráter classista no acesso ao fazer científico. Podemos fazer uma correspondência dessa consideração com as reflexões de Lowy (1982), quando este atribui a devida importância ao lugar de onde o cientista vê a realidade, podendo provocar uma visão mais ou menos ampla desta, sendo a classe social um dos elementos, se não o principal deles, que determina esta visão.

Até aqui já pudemos observar o um esboço de desconstrução da neutralidade da ciência, dada sua intrínseca relação de influência mútua com as relações sociais, com a inserção de classes dos sujeitos que fazem a ciência e que podem acessar conhecimentos produzidos nesse âmbito. Ainda que de maneira embrionária, a proposta de reflexão do presente artigo vai sendo desenhada.

Novamente remetendo a Marcuse (1967), este insiste em proclamar a relação entre tecnologia e relações sociais: baseado nas reflexões marxianas, traz que a transformação da natureza pressupõe a transformação do homem e isso tem implicações na sociedade. Nessa teia de relações, a ciência possui uma pretensa mas questionável neutralidade. Esclarece que, no entanto, o método científico e sua racionalidade, tal como construída na contemporaneidade, trouxe os elementos que provocaram a dominação do homem pelo homem. Isto por meio da dominação da natureza. Segundo ele, a tecnologia tornou-se grande veículo de espoliação. Ciência e tecnologia têm sido veículos da ideologia dominante. Esse papel ideológico oculta a relação de dominação entre as classes no capitalismo.

Também tendo como base o pensamento marxiano, István Mészáros rebate as críticas ao ponto de vista da totalidade, que apregoam a necessidade de que o conhecimento deva se dar apenas por recortes, pouco a pouco. Segundo ele, tais discursos são prenhes de uma ideologia que visa à manutenção da ordem capitalista, ordem dominante. Deste modo, qualquer possibilidade de olhar para a totalidade e que pense na subversão da ordem é tido como "irracional" e "emotivo", distante do gradual, como científico, racional, legítimo. Frigotto (2014) também empreende ponderações nesta direção dizendo haver uma ciência burguesa. Segundo ele, 
[...] como já nos alertou Marx, a "ciência burguesa", mediada pela ideologia que naturaliza as relações capitalistas, centra-se no entendimento de suas funções e disfunções internas e ignora o que historicamente a produz. Por isso mesmo, a ciência burguesa percebe os problemas concretos, como a desigualdade nos diferentes âmbitos humano-sociais, que é inerente à forma social capitalista, como uma mera disfunção e acaba sempre atacando, de forma focalizada, as consequências, e não as determinações" (FRIGOTTO 2014,p. 34)

Na passagem acima, podemos apreender alguns elementos importantes: o caráter de classe das ciências em geral também, de certa maneira, pensado por Marcuse e por Michel Lowy. Porque se temos uma ciência burguesa, temos uma ciência com posicionamento de classe. Outro elemento relevante é que se temos uma ciência burguesa, que não é "a ciência" em si, também temos possibilidade de outras formas para o fazer científico, que não seja privilegiando uma classe em detrimento da outra. E a ciência possui posicionamento político no âmbito das relações sociais. Embora não pareça, ela não é neutra.

O escrito acima nos remete à reflexão de que a ciência em si, de maneira isolada e a partir de uma suposta natureza, não produz a espoliação e o aniquilamento das relações. Ela é parte de um contexto histórico, social e político. A ordem capitalista produz efeitos nefastos para as sociedades humanas e a ciência é produzida nesse contexto, assim como poderia ser em outros contextos. Possui, portanto, direção ideológica, conforme repetimos aqui. Mas isso só se pode ser percebido quando nos reportamos a uma visão holística da realidade, evitando fragmentações.

Nesse sentido, Mészáros (2014), assim como Russell, reconhece a importância do modo científico de produção do conhecimento na quebra de paradigmas, tendo efeitos positivos e negativos para a vida no planeta. Ele o faz, entretanto, a partir de uma perspectiva que considera a produção científica como relacionada ao desenvolvimento das forças produtivas. Esse desenvolvimento é percebido por Marx como algo que poderia ser relevante para a emancipação humana, liberando-o do tempo de trabalho extenuante, possibilitando tempo para o desenvolvimento de seu potencial criativo. Essa afirmativa pode ser entendida quando buscamos uma melhor compreensão da teoria marxiana.

Na referida perspectiva, cabe salientar a defesa do materialismo histórico e dialético como método em Marx, o que afeta diretamente seu olhar sobre o fazer científico e sobre o papel da ideologia nas ciências.

Marx e Engels (2007) defendem que "não é a consciência que determina a vida, mas a vida que determina a consciência" (p. 20). Procuram demonstrar ao longo de suas obras como as condições materiais de existência e o desenvolvimento das forças produtivas culminaram em transformações nas relações entre os homens ao longo da história. 
Engels (2013) afirma que o trabalho criou o próprio homem, diferenciando-o dos outros animais. Com o desenvolvimento do trabalho e a influência sobre a natureza, temos o desenvolvimento de instrumentos. $O$ trabalho humano é ação intencional dirigida a um fim de antemão projetado. A finalidade inicial é suprir as necessidades humanas. E, para Marx e Engels (2007), a produção de meios para satisfação das necessidades é o primeiro fato histórico, a condição fundamental de toda história. Após isso são criadas novas necessidades. Para os autores, "[...] essa produção de novas necessidades é o primeiro ato histórico"(p.22). O desenvolvimento de forças produtivas para suprir novas necessidades sob a ótica do mercado induz o desenvolvimento da chamada divisão do trabalho, uma desigual distribuição do trabalho e de seus produtos e assim também temos o desenvolvimento da propriedade privada. Com tais elementos, o trabalho, a atividade é imposta ao homem, subjugando-o, estabelecendo relações de dominação entre eles. Temos a divisão da sociedade em classes.

Iasi (2013), inspirado na teoria de Marx e Engels, sintetiza que a humanidade é uma invenção do trabalho, e que este não acabará, ainda que vivenciemos um período de grande automação. Isso porque o trabalho é a singularidade do ser humano em sua relação com a natureza. Apenas o homem entre os animais modifica essa natureza para satisfação de suas necessidades e assim modifica-se a si mesmo. O homem tem intencionalidade em suas ações, projetando-as no que ele chama de objetivação ou ideação das ações humanas. O autor enfatiza que, graças ao trabalho, o humano se tornou ser histórico e social, desenvolvendo a comunicação como forma de compartilhamento das experiências acumuladas.

Friedrich Engels (2013) sinaliza que a demanda por controle sobre a natureza gerou necessidade de transformação completa na forma de produzir e consequentemente a ordem social vigente. Afirma ele:

[...] Em consequência, os interesses das classes dominantes e as classes dominantes converteram-se no elemento propulsor da produção, enquanto esta não se limitava a manter, bem ou mal, a mísera existência dos oprimidos. Isso encontra sua expressão mais acabada no modo de produção capitalista, que prevalece hoje na Europa Ocidental (p.28).

O autor demonstra como os interesses materiais condicionaram as relações humanas e que em cada período histórico as classes dominantes eram aquelas que tinham o "comando" da produção. Isto ainda pode ser pensado com relação à produção do fazer científico e os conhecimentos neste âmbito. Comandando o âmbito da produção, as classes dominantes também são prevalentes na produção de ideias. Em Marx e Engels (2007) vemos que os pensamentos da classe dominante de cada época são os pensamentos dominantes. Assim são processadas as relações também na ordem capitalista, a partir do desenvolvimento de forças produtivas que a engendraram e engendraram as contradições inerentes a ela. 
Em "O capital" (MARX, 2013), o autor fala sobre o trabalho como parte da ontologia do ser social, para suprimento de necessidades como trabalho necessário, que existe em toda e qualquer sociedade. Frigotto (2014) esclarece que a luta dos seres humanos é na direção da existência do trabalho para liberdade. Isso implica na redução do tempo de trabalho para produção e reprodução da vida, para suprimento de necessidades,o que é permitido com o desenvolvimento das forças produtivas e, entre elas, podemos dizer, a do fazer científico e da tecnologia.

No caso da moderna sociedade burguesa, o desenvolvimento das forças produtivas inaugura relações de troca entre mercadorias que afetam diretamente as relações entre as pessoas. Temos o desenvolvimento da forma mercadoria, que contribui para a construção de relações de classe distintas do período feudal. A forma-mercadoria traz à tona atribuições de valores de uso e de valor de troca às coisas. A atribuição de valor se dá tendo como base o tempo de trabalho socialmente necessário para produção de mercadorias. O próprio trabalho também se torna uma mercadoria e pode ser vendido no mercado. Relações mercantis permeiam a formação da moderna sociedade burguesa. (MARX e ENGELS, 2007; MARX, 2013).

Com a industrialização (que ocorreu com mais vigor inicialmente na Inglaterra devido a condições materiais vivenciadas naquele país), houve mudanças nas forças produtivas e no próprio tempo necessário para produção de mercadorias. As relações entre os homens se alteraram também. As manufaturas e as relações ali desenvolvidas deram lugar ao trabalhador livre que individualmente venderia sua mão-de-obra no mercado. $O$ trabalho não apenas como algo necessário, mas como mercadoria. Homens produzindo não apenas para satisfazer suas necessidades ou produzindo para satisfazer as necessidades dos seus, mas para satisfazer as de outras pessoas, com as quais não mantinham relações pessoais. E homens que "compram" tempo de trabalho de outros.

Aquilo que era produzido pelas mãos do humano deixa de ser percebido como produto de seu trabalho. Está distante do trabalhador. Afinal, ele está nas fábricas, desenvolve um trabalho que muitas das vezes está "parcelado" ou "dividido", não participa de todo o processo de produção de determinados artigos como outrora. Ele produz "partes" ou opera maquinaria. O trabalho deixa de ser apenas algo considerado como parte da ontologia do ser social e pode também ser um trabalho que aliena o homem e o aparta de sua própria produção e faz com que ele produza para que outrem obtenha lucro. Marx problematiza que o fetiche da mercadoria é fazer com que relações entre homens pareçam relações entre coisas, porque a mercadoria é produzida pelo trabalhador, mas levada ao mercado como uma coisa apartada dele, como posse daqueles que possuíam os meios de produção. São relações aparentemente de troca que não permitem que sejam percebidas as relações de produção.

Em suas obras, Marx destaca as relações de dominação existentes ao longo da história, enfatizando a história de luta de classes. Para ele, na socie- 
dade burguesa a própria burguesia aparece como classe dominante, e a classe trabalhadora ou proletariado com a classe dominada. A burguesia é classe dominante porque domina os meios de produção e por isso suas ideias aparecem como ideias dominantes.

Percebemos aqui a lógica impressa por Marx sobre as relações entre ideias e interesses materiais: Quando há transformações nas condições de vida dos homens, como consequência há alteração de suas consciências e não o contrário. Para defender o materialismo em sua perspectiva, o autor citado desenvolve esse argumento de maneira bastante criteriosa em "A ideologia Alemã", texto escrito junto com Friedrich Engels.

No contexto da moderna sociedade burguesa, a própria ciência desenvolveu-se, e com a revolução industrial temos uma nova forma de relacionamento entre ciência, tecnologia e indústria. A vida humana aparece como mercadoria. A obtenção do lucro é o objetivo maior do sistema. O capitalismo é prenhe de contradições, sendo a crise inerente a ele. Frigotto (2014) destaca algumas dimensões relativas às crises no âmbito da ordem social vigente, entre as quais: o "esgotamento de sua capacidade civilizatória" e o potencial cada vez maior de produção de mercadorias, "concentração de riquezas, de conhecimento e poder e sua incapacidade de distribuir e socializar a produção para o atendimento das necessidades humanas básicas" (p.47).

Mészáros (2014) observa que o fim dos problemas existentes na ordem vigente é atribuído ao avanço da ciência e da tecnologia e com o aumento da produção. Para Frigotto (2014), esta mistificação interfere também no âmbito das ciências humanas, que interpretam que o fim das desigualdades advirá do combate a suas consequências e não necessariamente a suas causas, propondo intervenções focalizadas em muitas ocasiões. Conforme já dito, no âmbito da teoria marxista, a ciência é vista como um aspecto do desenvolvimento e sujeita às contradições do capitalismo. Ele não vê a ciência isolada das relações sociais no âmbito desse sistema.

Michel Lowy (1982) e István Mészáros (2014) refletem então que a caricatura da ciência como um constructo sem historicidade tem como objetivo mascarar seu caráter ideológico e classista. Aqui temos exemplos de relações fetichizadas, que demonstram-se mais acirradas no âmbito do sistema capitalista.

\section{Capitalismo, luta de classes e alternativas à ciência burguesa.}

Mészáros (2014) brinda-nos com suas reflexões, esclarecendo que a subordinação do valor de uso ao valor de troca (e suas consequências destrutivas) não está na natureza da ciência e da tecnologia. Esse valor de troca surge muitas das vezes indiferente ou mesmo oposto às necessidades humanas, "[...] apropriando-se, sem levar em conta as consequências, dos recursos materiais e intelectuais finitos da sociedade em sua qualidade de antivalor de uso necessariamente auto-orientado e autoperpetuador" (p.269). Os problemas e obje- 
CIÊNCIA E RELAÇÕES SOCIAIS NO CAPITALISMO:

ELEMENTOS PARA O DEBATE

tos de pesquisa, as descobertas e os objetivos estão relacionados com o modo de produção capitalista. Não está em um "vácuo social", obedece, na maioria das vezes, às exigências do mercado, sobretudo quando falamos nas ciências naturais. Tanto que a ciência teve um grande crescimento no modo de produção capitalista, com investimentos para sua expansão. A ciência pode servir a essa expansão, pois foi demasiadamente relevante para o desenvolvimento de potencialidades positivas e das destrutivas do referido modo de produção.

Lowy (1982) contextualiza que na ordem capitalista as ciências naturais desvinculam-se da religião e se desideologizam. Têm como ideal a neutralidade baseada na isenção de juízos de valor e relações políticas. Mas vivemos em um contexto de produção de necessidades e exploração do trabalho humano. Contexto de produção que desconsidera a vida humana, porque o importante é a obtenção do lucro, a expansão do capital. E neste contexto, os interesses econômicos em que as pesquisas - muito mais no caso das ciências naturais - precisam de financiamentos, as escolhas que parecem neutras ou livres de influências externas são demasiadamente influenciadas pelos citados interesses. Em Mészáros (2014) temos o complemento desse raciocínio, dizendo que grande parte dos cientistas naturais está na base de apoio do complexo militar -industrial justamente por precisarem de maiores financiamentos. E por isso têm seu potencial de criticidade ao sistema reduzido em relação aos cientistas sociais. Ele afirma que a ciência não é um agente soberano e auto-suficiente, apenas atende às necessidades do complexo militar-industrial. Lowy traz à tona, por exemplo, que pesquisas em saúde são financiadas por militares a partir de seus interesses. Isso está relacionado com a mercantilização da vida, típica da ordem burguesa.

Neste contexto de mercantilização, temos o crescimento do consumo destrutivo. O capitalismo conseguiu ter como sinônimos o consumo e a destruição da natureza. Isso quer dizer que:

Em outras palavras, destina uma porção maciça e sempre maior dos recursos materiais e humanos da sociedade a uma forma de produção parasitária e autoconsumidora que está tão radicalmente divorciada das - e, na verdade oposta às - necessidades humanas reais e do correspondente consumo, que pode considerar sua justificativa racional e objetivo último, não menos contraditório e desumano do que a destruição total da humanidade. (MÉSZÁROS, 2014, p. 297).

A produção da ciência e da tecnologia, em grande parte, segue na direção acima mencionada pelo autor húngaro.

O brasileiro Gaudêncio Frigotto (2014) ilumina nossas reflexões fazendo-nos atentar para a atual mundialização do capitalismo e difusão de seus interesses, da sociabilidade construída em seu seio, das desigualdades que são sua consequência. Segundo ele, este capital "[...] concentra nas mãos um nú- 
mero cada vez menor de grupos econômicos o conhecimento, a tecnologia, a riqueza e o poder sobre a vida humana, ampliando de forma escandalosa o apartheid social entre nações e dentro delas" (p50). Essas desigualdades têm a ver com desigualdades entre as classes e os impactos da ordem capitalista para cada uma delas. A mundialização do capital tem efeitos sobre a divisão social do trabalho e consequentemente para a construção dos conhecimentos conforme já indicado aqui. Também têm efeitos sobre subjetividades, sociabilidades, e isso não pode ser desconsiderado, como bem aponta Lowy.

Corroborando com a ideia expressa acima, Mészáros (2014) fala sobre a ideologia do cientificismo aparentemente sem ideologia, cujas práticas produtivas manipuladoras alcançam os cotidianos dos seres humanos em geral, levando as práticas dominantes para estes âmbitos. Mas essa ideologia não é invenção da ciência. A ciência guarda alternativa. Inclusive, para o autor, ela também é afetada pela crise estrutural do capital, tal como já anunciado por Frigotto.

Falando em alternativas, cabe aqui salientar um aspecto do método marxiano que chama a atenção pela proposta revolucionária. Por não vincular-se à ideia de neutralidade, por calcar-se no movimento da totalidade da vida social e vincular-se ao concreto e ao histórico, a teoria propõe um caráter transformador para a produção do conhecimento: conhecer para transformar a realidade. Konder (2011) expressa bem esse movimento:

Em última análise, a validade do conhecimento não pode ser medida em um plano puramente teórico, que se abstraia completamente da vida prática. O conhecimento é um momento necessário da transformação do mundo pelo homem e da transformação do homem por ele mesmo. A tarefa de interpretar o mundo faz parte da tarefa maior de modificá-lo. (p.52).

A modificação da ordem vigente, para Marx, está baseada no que ele chama de luta de classes. Trata-se de um processo que, para Frigotto (2014), tem seu gérmen na própria sociabilidade do capital e visa superá-lo. Lowy (1982) dá pistas sobre a importância desse processo, anunciando que no interior das ciências é possível que se tenha uma visão mais ampliada da realidade a partir do ponto de vista da classe histórica, o proletariado, uma ciência vinculada à sua visão de mundo. Ele admite que as dimensões da realidade sejam percebidas pelo cientista dependendo do lugar que este ocupa. Isso quer dizer que, por mais que o cenário hoje seja aquele apresentado em parágrafos anteriores, não é algo que não possa ser superado. Pelo contrário. A teoria marxista é calcada na ideia de transformação, o que significa dizer que o fazer científico e a tecnologia podem ser realizados em outras bases. Eles não são emancipadores ou destruidores por "natureza", mas fazem parte de construções sociais e da ordem vigente.

Mészáros (2014) e Frigotto (2014) apostam na ação coletiva da classe proletária, na direção do fim do domínio entre as classes e da emancipação 
CIÊNCIA E RELAÇÕES SOCIAIS NO CAPITALISMO:

ELEMENTOS PARA O DEBATE

humana. O proletariado como sujeito histórico e com uma visão mais abrangente da realidade pode ser a classe que enfrentará a barbárie estabelecida pela expansão capitalista. lasi (2011) também aposta na dinâmica da luta de classes, em que:

[...] se combinam elementos objetivos e subjetivos que podem levar a formação do proletariado enquanto proletariado, ou seja, mais do que simplesmente uma classe da sociedade do capital, uma classe contra o capital, que é capaz de anunciar um novo tipo de sociabilidade humana finalmente emancipada. (p.8)

Iasi (2013) se constitui como um autor relevante para que possamos compreender do que se trata a "emancipação humana" na teoria marxista. Ele pondera que o trabalho é condição ontológica do homem como ser histórico e social, e que em algum momento ele torna-se motivo de sofrimento para o homem. Esse momento ocorre quando temos o alvorecer da forma-mercadoria e o fortalecimento das relações mercantis e o fetiche que faz com que relações entre homens apareçam como relações entre coisas. Esse estranhamento já exposto aqui faz com que aquilo que é produzido pelo homem volte a ele como algo hostil. Isto não é diferente no caso da produção científica. A riqueza de alguns se torna carência de outros. A referida forma de produção altera a sociabilidade humana. A emancipação ocorre quando ao homem são restituídas as relações que lhe são próprias. No capitalismo, o produto do trabalho pertence a outro. Torna-se martírio para o homem que trabalha e motivo de fruição para outras pessoas.

O autor diferencia, assim como em Marx, emancipação política e emancipação humana. A primeira ocorre no terreno dos direitos e nos limites da sociabilidade burguesa. A segunda traz como pressupostos a socialização dos meios de produção, proibição da compra e venda do trabalho. Neste caso, recursos necessários são parte do patrimônio coletivo. Segundo lasi (2013):

[...] Só podemos falar de emancipação humana na medida em que os produtores livremente associados possam de fato escoIher o ponto em que irão se inserir em uma divisão do trabalho, o que pressupõe certa homogeneização das formas particulares que compõem o trabalho social total. Tal homogeneização supõe, portanto, certo grau de desenvolvimento tecnológico, capaz não apenas de fazer com que esforços iguais produzam resultados de intensidade e impactos distintos, como de fato, eliminar certas atividades que nenhum ser humano deveria ser obrigado a fazer. (pp 57-58)

Percebemos aí a importância atribuída pela teoria marxista à colaboração da tecnologia para a emancipação humana. Emancipação esta que requer também o término do antagonismo entre trabalho intelectual e trabalho ma- 
nual e a reunificação entre a intencionalidade e a ação por meio da socialização do conhecimento socialmente produzido e da educação. $O$ trabalho, neste sentido, precisa deixar de ser apenas um meio de vida para o humano.

Pensando em sociabilidade emancipada, podemos dizer que aí sim seria possível uma ciência emancipada, ou que contribuirá para a manutenção de uma humanidade emancipada. Para lasi (2011), a emancipação está na liberdade criativa, naquela em que o trabalho não mais será tido como mercadoria, não mais aliene o humano. $O$ trabalho ocorre para seus objetivos relacionados ao valor de uso e com tempo reduzido. Também acrescentamos que nesse novo contexto o humano vivencie diferente relação com a natureza e o consumo e a própria ciência contribua para tal. O problema, portanto, não é a ciência, a tecnologia ou o desenvolvimento das forças produtivas, mas o contexto em que elas ocorrem influenciando seus objetivos e no modo como ocorrem. Na teoria marxiana, o desenvolvimento das forças produtivas é condição necessária para que emancipação humana seja possível. Para que o homem tenha meios de desenvolver-se enquanto ser genérico, de desenvolver suas potencialidades humanas, é importante que tais forças produtivas estejam suficientemente avançadas a ponto de libertá-lo do tempo de trabalho para produção de necessidades para que essa produção seja suficiente para satisfazer as demandas de toda a humanidade, de modo que não faltem meios para reprodução de sua vida. O mesmo poder-se-ia dizer acerca da ciência e da tecnologia.

Elas - ciência e a tecnologia - podem reinventar-se em uma nova ordem econômica, política e social, contribuindo para a liberdade e emancipação da humanidade. Mas isto não será possível enquanto perdurar o capitalismo como modo de produção privilegiado.

\section{Considerações finais}

Diante do exposto, traçamos um roteiro de posicionamento no que tange à correspondência entre ciência e relações sociais. Buscamos demonstrar que o argumento da neutralidade contribui para uma visão não histórica e descontextualizada, como se o fazer científico e a produção de conhecimentos estivesse descolada do movimento da realidade, da ordem social vigente.

Vimos que a ciência e a tecnologia estão vinculadas à citada ordem, e não ocorrem em um "vazio" ou de modo autônomo. Estas têm implicações sobre as relações sociais e implicam as relações sociais. Têm relação com o desenvolvimento das forças produtivas em cada modo de produção. Portanto, não possuem uma "natureza" boa ou má, uma natureza positiva ou destrutiva para a humanidade. Os "efeitos" da produção do conhecimento científico têm relação com o próprio contexto de sua produção e os objetivos engendrados neste contexto. Para apreendê-lo, faz-se necessária uma visão holística, não fragmentada da realidade e que consiga desvelar seu movimento e desmistificar os fetichismos produzidos no âmbito do capitalismo, em que relações entre pessoas apa- 
CIÊNCIA E RELAÇÕES SOCIAIS NO CAPITALISMO:

ELEMENTOS PARA O DEBATE

recem como relações entre coisas. Em que o valor de uso está subordinado aos valores de troca. Em que a vida e o trabalho são mercantilizados.

Entender que a produção do conhecimento está inserida nas relações políticas, econômicas e sociais é fundamental para que essas relações sejam transformadas e para que o fazer científico possa ter outros usos e implicações na vida humana.

Pensando nas alternativas, estas estão voltadas para o processo da luta de classes e na direção da emancipação humana. Estão voltadas para ações coletivas que tenham como horizonte a superação da ordem capitalista, em que não é possível essa emancipação, porque a citada ordem existe através de sua auto expansão e das relações mercantis e de exploração do trabalho.

Voltando à canção de Gil, ela nos inquieta, e pode-se dialogar com ela, mediante reflexões aqui empreendidas no seguinte sentido: não se trata do que eles vão fazer com as novas invenções, mas do que todos farão para que as novas invenções sejam vistas como pertencentes à humanidade, usufruídas por todos e todas. Isto quer dizer que todos os seres humanos estão inseridos nesse sistema que aniquila e cabe que coletivamente haja uma luta para sua superação. Apenas com a instauração de uma nova ordem será possível que a ciência tenha "implicações" na emancipação do homem. E que aqueles que produzem conhecimento consigam ter a visão do lugar do proletariado e contribuam para essa nova ordem, participando da construção do seu gérmen ainda na sociedade capitalista.

\section{Referências}

ENGELS, Friedrich. Sobre o papel do trabalho na transformação do macaco em homem. In: ANTUNES, Ricardo (org). A dialética do trabalho - escritos de Marx e Engels. Volume I. São Paulo: Expressão Popular, 2013.

FRIGOTTO, Gaudêncio. As novas e velhas faces da crise do capital e o labirinto dos referenciais teóricos. In: FRIGOTTO, Gaudêncio; CIAVATTA, Maria (orgs). Teoria e Educação no labirinto do capital. 2 ed. São Paulo: Expressão Popular, 2014.

IASI, Mauro. Ensaios sobre consciência e emancipação. 2 ed. São Paulo: Expressão Popular, 2011.

IASI, Mauro. A maldição e a emancipação do trabalho (Ou como a humanidade dançou e como ela pode dançar). In: SILVA, J.F.S. et al. Sociabilidade burguesa e serviço social. Rio de Janeiro: Lumen Juris, 2013.

KONDER, Leandro. Marx - vida e obra. 7 ed. São Paulo: Paz e Terra, 2011.

LOWY, Michael. "As paisagens da verdade e a alegoria do mirante". In: As aventuras de Karl Marx contra o Barão de Munchhausen. São Paulo: Busca Vida, 1982, p. 187-210.

MARCUSE, Herbert. "Do pensamento negativo para o positivo: racionalidade tecnológica e a lógica da dominação". In: Ideologia da sociedade industrial. Rio de Janeiro: Zahar, 1967, p. 142-162.

MARX, Karl. A Mercadoria. In: O capital: crítica da economia política. São Paulo: Boitempo, 2013.

MARX, Karl; ENGELS, Friedrich. A ideologia alemã. 3 ed. São Paulo: Martins Fontes, 2007.

MÉSZÁROS, István. Parte II: Ciência, ideologia e metodologia. In: O poder da ideologia. São Paulo: Boitempo, 2014.

RUSSELL, Bertrand. "Ciência e tradição" e "Efeitos gerais da técnica científica". In: O impacto da ciência na sociedade. Rio de Janeiro: Zahar, 1976, p. 9-52. 